\title{
ESTUDIOS DE TRADUCCIÓN, HOY
}

\author{
Luis Pegenaute - Universitat Pompeu Fabra - Barcelona ${ }^{1}$
}

\begin{abstract}
RESUMO: This text is, originally, the formal presentation to the book Traducción, (sub)version, transcreación , edited by Camps, A .; Hurtley, J. and Moya, A. (PPU, Barcelona, 2005). As a speech, it was delivered during a special launching session held at the Universitat de Barcelona, in March 15, 2005. The referred publication has been conceived as a due homage to the professional performance of the Brazilian poet, critic and translator Haroldo de Campos, and is part of the research activities developed both by the investigation thematic net "La traduccion literaria en la época contemporánea" (XT03-34), coordinated by Dr. Assumpta Camps (UB-Spain), and the Projeto 047/03 CAPES/MECD "Estudos de Literatura Comparada, Tradução e Terminologia: América Latina e Espanha", coordinated by Dr. Tania F. Carvalhal (UFRGS-Brasil).
\end{abstract}

PALAVRAS-CHAVE: Translation Studies. Original. Literary transcreation.

En este volumen encontramos una veintena de trabajos reunidos bajo un título que hace explícita su intención en la referencia inequívoca a la obra de Haroldo de Campos, al que además, los editores, han querido dedicar la obra. Assumpta Camps ha sabido en el estudio introductorio precisar con tino cuál es la toma de posiciones desde la que se parte, presentando de forma coherente cuál es la relación que se establece entre autores hoy tan consagrados como son Walter Benjamin, los propios hermanos de Campos y Derrida, sin dejar de pasar revista a aproximaciones hoy candentes en los Estudios de Traducción, como son la política de género y la política postcolonial, lo que en buena medida es sinónimo de reconocer el sesgo postestructuralista que se le quiere dar al libro. A nadie debe extrañar, por tanto, que encontremos en la obra estudios en los que se analiza, por ejemplo, el modo en que un escritor polaco Gombrowicz - se autotraduce al castellano en compañía de un grupo de amigos argentinos que no entendía el polaco; las dificultades de traducción que plantean los escritos de un filósofo francés —Derrida— para el cual la traducción era una tarea necesaria y a la vez imposible; la traducción de poetas franceses — como Reverdy - cuyo carácter vanguardista introduce elementos de consideración importante para el debate entre traducibilidad e intraducibilidad; la problemática de la traducción de la literatura postcolonial, literatura de carácter híbrido, en la que se dan ecos de voces superpuestas, etc.

Los Estudios de Traducción han ocupado hasta hace bien poco una posición periférica en el análisis de la literatura. Afortunadamente, el panorama ha cambiado radicalmente en las tres últimas décadas. A pesar de la trascendental importancia de la traducción literaria como actividad intercultural, ramas de las humanidades como la critica y teoría literaria, la teoría de la comunicación, la lingüística o la poética, consideraron a menudo tales estudios algo absolutamente marginal a sus intereses. La causa más importante de este olvido o indiferencia no ha sido otra que la tradicional valoración de la traducción como un mal necesario que intentaba paliar las limitaciones que el hombre encontraba a la hora de establecer contactos con individuos pertenecientes a otras comunidades lingüísticas y con las herencias culturales legadas por aquellos en soporte escrito. Era, por así decirlo, una manera de recordarnos lo imperfecto de nuestra naturaleza. Esta concepción implicaba una importante paradoja, pues otorgaba a las obras literarias, en particular a las grandes obras que conforman la literatura canonizada y que supuestamente han de presentarse como modelos dignos de imitación, el dudoso honor de ser inimitables y, mucho menos, irrepetibles. Ello redundó en recurrentes e indiscriminadas comparaciones fiscales entre los originales y sus traducciones para ver cuánto distaban estos de aquellos y denunciar así qué se había perdido en el inevitable, pero también doloroso trasvase interlingüístico. Desde esta perspectiva, no resultaba extraña la costumbre de considerar de manera apriorística y, por tanto, infundada, que toda obra es cualitativamente superior a su traducción.

Cabe preguntarse incluso qué hemos de entender por original. En este sentido ha sido fundamental la contribución hecha por Walter Benjamin ya en 1923, en su famosa introducción a la versión alemana de Tableaux Parisiens, de Baudelaire, recuperada más tarde por los desconstruccionistas y teóricos postestructrualistas de la traducción. En tal ensayo, Benjamin utiliza el concepto de traducción como continuación de la vida. Derrida, por su parte, siguiendo a Benjamin, se cuestiona la licitud de asumir a priori la supremacía del texto extranjero. Así, en "Des Tours de Babel" afirma que tal texto no es en absoluto un original, sino que es en sí mismo una traducción, ya

${ }^{1}$ Luís Pegenaute é professor Decano da Faculdade de Tradução e Interpretação da Universitat Pompeu Fabra (UPF), de Barcelona, Espanha. 
que al fin y al cabo no deja de ser una interpretación o, incluso, una paráfrasis de una idea. No será algo cerrado o finito, sino el comienzo de una vida que será eterna mientras el texto sea traducido. Al desechar la dicotomía entre original y traducción, carece de sentido asignar a esta última un status secundario. En opinión de los postestructuralistas, lo que hace original a un texto escrito en otra lengua es el hecho de que es digno de ser traducido, pero ello entraña una cierta paradoja, pues le hace depender de su traducción para lograr su canonización. Todo esto indica que el texto original no es algo autosuficiente, completo e independiente. Los postestructuralistas propugnan que lo que tradicionalmente se entendía por original es en realidad una traducción, en cuanto que deriva y depende de la percepción del autor y supone la elaboración de un significado, un concepto. El hecho traductor se convierte en una actividad que permite a un determinado texto perpetuar su vida en otro contexto, y el texto traducido adquiere el status de original en virtud de su existencia en ese nuevo contexto. En este sentido, no está de más señalar que, por ejemplo, en Rusia, grandes autores como Pushkin, Dostoyevsky, Turgenev, Buni, Pasternak, etc. han desempeñado repetidamente el noble cometido de la traducción y muchos de ellos sólo se han considerado en verdad escritores una vez que sus obras han sido traducidas.

No cabe duda de que en toda traducción, como acto de (re)creación que es, afloran las idiosincrasias personales del traductor, sus convicciones estéticas, su concepción del mundo, su interpretación de la literatura y de la obra literaria que está vertiendo a otro idioma. Ahora bien, tal y como señala Venuti, aunque toda su experiencia pueda encontrar reflejo en la traducción, en términos de originalidad, a su trabajo no se le suele otorgar la misma posición jerárquica que la copia hecha por el autor, la "copia autorizada". Ello es debido a que al traductor se le exige la autoinmolación; se le pide que desaparezca todo vestigio de su quehacer traductor en la versión que él presenta, de tal manera que el receptor se encuentre ante un espejismo, una ilusión de la imaginación: un autor extranjero escribe en nuestro propio idioma. De este modo, muchos traductores anhelan el anonimato para así conseguir la fama, considerando que si no se hace referencia a su persona, si no se ve la huella de una pluma intermedia, es porque la traducción está bien hecha.

Se suele tener la convicción de que el texto traducido ha de parecer original; para ello se ha de lograr una transparencia, una fluidez que sólo resulta posible tras la aplicación constante de una serie de estrategias de trasvase, cuya última finalidad es despojar a la obra original, (mantendremos la terminología tradicional porque nos es útil y familiar) de todo lo que pudiera parecer exótico o heterodoxo, tanto en el ámbito estético como en el ideológico. En lo que respecta al primero, vemos que, en términos generales, prescindiendo incluso de los condicionantes impuestos por la poética imperante en todo sistema literario en un momento dado de su evolución, se suele aspirar a una sintaxis lo más lineal posible, a la unicidad del significado o al menos a una ambigüedad controlada, a la consistencia lingüística, a los ritmos conversacionales, etc. Por el contrario, se suelen evitar aquellas construcciones que no resulten corrientes, la polisemia, los arcaísmos, los idiotismos y giros dialectales, los cambios bruscos en el tono o la dicción, la aliteración, etc., en definitiva, todos aquellos efectos de índole estilística y textual que nos hagan reflexionar sobre la materialidad del lenguaje. En lo que respecta al factor ideológico, vemos que el traductor se encuentra en una posición priviliegiada para manipular, si lo considera conveniente, el texto original y adaptarlo al universo cultural del sistema meta, sea para salvaguardar los valores éticos, morales, políticos, religiosos o de cualquier otro tipo sobre los que éste se sustenta o simplemente para no transgredirlos. En todo caso, de ello depende en gran medida la canonización de su traducción y su inclusión en lo que se considera literatura oficial.

Tal y como señala Lefevere, la cuestión de la canonización de las obras literarias (y también de las versiones extranjeras resultantes de su reescritura) ha de ser considerada en conjunción con una serie de factores determinantes: a saber, el tipo de ideología, poética, grado de institucionalización, censura, etc. del sistema cultural en cuestión. Tanto la selección del material que va a ser sometido a un trasvase interlingüístico como el propio proceso traductor que va a tener lugar, varían en función de la mayor o menor influencia de tales cuestiones. Su importancia no acaba aquí, pues también condicionan su posterior recepción y la atribución, aunque sea temporal, de un determinado status, que se verá modificado diacrónicamente conforme los propios condicionantes vayan cambiando de naturaleza.

Como consecuencia de los comportamientos correctores antes descritos, muchos de los rasgos más personales de algunos escritores, que en definitiva son los que constituyen sus idiolectos particulares, son "suavizados" o convenientemente "adaptados" en el trasvase interlingüístico. El traductor sólo puede mantener las características idiosincráticas del autor si el sistema meta lo permite, tanto en su vertiente lingüística, como literaria y cultural. Para cumplir su cometido ha de valerse de su percepción de lo que Poggioli denominaba "mímesis literaria", pues resulta imposible proponer unas pautas aplicables a todas las realizaciones concretas. El componente lingüístico se encuentra inexorablemente unido al factor cultural y estético y no resulta factible formular una teoría que cubra todas las situaciones posibles. El quehacer de los traductores coetáneos, a pesar de la variedad intrínseca a todo acto de recreación personal, refleja a menudo similitudes relevantes como consecuencia de los dictámenes de la estética imperante en ese momento. No es extraño que las traducciones configuren una referencia inevitable en el campo de 
la Literatura Comparada ya que nunca constituyen actuaciones aisladas o caprichosas, sino que son reflejo de tradiciones literarias.

En todo caso, a pesar de la normalización a que son sometidas numerosas obras durante su trasvase, no hemos de desdeñar el carácter interpretativo que supone todo quehacer traductor. La traducción, como recreación que es, y, por tanto, acto individualizado y personal, permite establecer incontables variantes de un mismo texto. La disimilitud de estas variantes prueba que numerosos textos literarios admiten distintas interpretaciones. En palabras de Schogt, "el mismo traductor puede tratar diferentes textos de diferentes maneras y el mismo texto puede ser tratado de diferentes maneras por diferentes traductores".

El concepto de traducción como recreación está íntimamente ligado a las cuestiones de libertad y determinismo. Cuando emprendemos la lectura de una obra, hacemos uso de nuestros inventarios lingüísticos y nuestra experiencia extralinguística, es decir, nuestro conocimiento del mundo. Ambos aspectos difieren de persona a persona y, por consiguiente, la percepción e interpretación del texto nunca será la misma. Esto ha dado lugar en la crítica moderna a la consideración de que sin lector no hay texto. Así, por ejemplo, Iser, defensor junto a Jauss y otros de lo que se ha dado en llamar "teoría de la recepción", caracteriza la interacción entre lector y texto en términos de una dialéctica continua. Al postular que el lector reorganiza dialécticamente los segmentos textuales, se invalida el modelo unidireccional de lectura, se asume que comprensión y creación son términos sinónimos y se subraya su papel fundamental a la hora de dar vida a un texto. Tal supuesto plantea cuestiones de trascendental importancia en el campo de la traducción literaria. Si se enfatiza el aspecto interpretativo de la traducción, carece de sentido cuestionarse cuál es la verdadera identidad del Texto Original y obvia toda discusión sobre la calidad de las traducciones, ya que sólo es posible comparar interpretaciones, y no hay nada más subjetivo y parcial que esto, pues generalmente se consideran mejores las interpretaciones que más se aproximan a las propias.

En términos generales, se ha ido avanzando mucho en el estudio de cómo la traducción puede amoldarse a los gustos imperantes o servir como catalizador de nuevas tendencias literarias. En tiempos recientes, la teoría polisistémica desarrollada por Even-Zohar ha servido para proporcionar un constructo teórico que dé razón de este papel de la traducción. Basándose en los presupuestos defendidos por los formalistas rusos, proponía una visión de la literatura como una pugna permanente entre las fuerzas más conservadoras y las más innovadoras, con la traducción aliándose en uno u otro bando, ya fuera consolidando o minando los modos discursivos establecidos. Desde esta perspectiva, la traducción entraba a formar parte de un amplio esquema, conjuntamente con otras formas de expresión antes desdeñadas, como son la literatura popular, la tradición oral o la literatura infantil. Este panorama se amplió aun más con el advenimiento del giro cultural en los años 90, cuando se puso de manifiesto la capacidad de la traducción para contribuir a la constitución de identidades culturales. La selección de los textos que van a ser traducidos, al igual que los modos en que las traducciones individuales constituyen construcciones que vienen a representar los productos culturales extranjeros, y de hecho, entendido en un sentido más amplio, las culturas extranjeras. Por otra parte, el estudio de las traducciones no cabe duda de que nos puede proporcionar una visión privilegiada de las definiciones que nosotros nos marcamos de nuestra propia cultura, ya que los procesos de inclusión o exclusión del "otro", a la vez que la elección de los modos particulares de representación de esa otredad, son indicios muy claros de los valores autóctonos imperantes.

Contamos con críticos como, por ejemplo, A. Lefevere que se han ocupado poner de manifiesto el papel de la poética y la ideología como factores de control institucional. El reconocimiento de que la traducción implica la importación de textos desde fuera de una determinada esfera y, por lo tanto, la importación de elementos potencialmente subversivos, ha llevado — según Lefevere - a que desde el poder siempre se haya dado una inquietud por controlar y regular la traducción. Otros teóricos que participan del denominado giro cultural experimentado en los Estudios de Traducción, como son las autoras feministas, hablan del hecho de que la traducción siempre se ha visto con cautela por el hecho de que amenaza con hacer desaparecer la diferencia existente entre producción y reproducción y que resulta esencial para el establecimiento y mantenimiento del poder. Algunas autoras feministas han buscado inspiración en críticos postestructuralistas como Foucault para poner de manifiesto cómo se ha mantenido encerrada perpetuamente a la traducción en un ámbito legal y jerárquico en el que de forma sistemática se privilegia jerárquicamente al original sobre la obra traducida.

La irrupción del postestructuralismo consistió en un constante cuestionamiento sobre la traducción. Pone en seria duda la posibilidad de la traducción llamando la atención a la inestabilidad del significado, la materialidad del lenguaje y el tipo de efecto creado por los textos que son multilingües. Se llega a la paradoja de que la traducción es necesaria pero imposible, lo que está en sintonía con el hecho de que pone de manifiesto el modo en que es una quimera teorizar sobre la traducción desde fuera del ejercicio. Del mismo modo que parece borrar las fronteras en la creación original y la crítica, de igual modo cuestiona la posibilidad de separar el objeto de estudio de la reflexión en torno a él. 
La aportación hecha por el poestructuralismo demostró ser muy beneficiosa, propiciando el advenimiento del feminismo y el postcolonialismo. Ambas corrientes están preocupadas con la ética y la identidad. Las dos han considerado a la historia de la traducción como un terreno abonado para el conflicto. Ambas se fijan tanto en lo que se incluye en la traducción como lo que queda fuera de ella, tanto las manifestaciones explícitas de comportamiento como las implícitas, del mismo modo que se fijan en las grandes estructuras de poder subyacentes a los comportamientos individuales. Siguiendo el ejemplo de los estudios de género, las estudiosas de la traducción feministas han puesto de manifiesto, por ejemplo, el modo en que los sistemas educativos y sociales permitían el acceso de algunas mujeres a la traducción, pero no a la escritura original; del mismo modo que se les permitía traducir según qué libros. Los estudiosos postcolonialistas, por su parte, reconsideran la imagen que occidente se ha forjado del resto del mundo, analizando la traducción como instrumento de dominación.

$\mathrm{Ni}$ los estudios de género ni los postcoloniales distinguen de forma absoluta entre lo que es literario y lo que no. Todas las formas discursivas parecen contribuir a la construcción de identidades en las diferentes comunidades. Esto pone en un primer plano la identidad del investigador/a. Tanto los postcolonialistas como las feministas hablan desde la perspectiva de quien se sabe perteneciente a una minoría a un grupo social. Por otra parte, ambas corrientes críticas están interesadas en formas literarias muy particulares: la écriture féminine y la escritura híbrida. Una y otra suponen un auténtico reto de traducción, pues evocan formas de experiencia muy determinadas. En el primer caso, encontramos un lenguaje corporal alejado del discurso masculino; en el segundo, se evoca la memoria de las lenguas autóctonas, ya sea mediante la memoria de quien ha dejado de usarlas o mediante una auténtica mezcla multilingüe. Como formas de expresión híbridas que son dan lugar a identidades complejas y polimorfas.

En los estudios que hoy tenemos el privilegio de presentar encontramos numerosos ecos sobre todas y cada una de las cuestiones que les vengo comentando. No dudo que este volumen, digno sucesor de Ética y política de la traducción en la época contemporánea constituye un importante paso adelante en el debate que hoy se ha fraguado en el seno de la disciplina, poniendo de manifiesto la fructífera relación investigadora mantenida por la Universidade do Rio Grande do Sul y la Universidad de Barcelona en materia de traducción. 